If no obvious cause for subfertility is found then the timing of referral to a specialist centre is important and should take account of the woman's age and the duration of subfertility. The longer the patient remains childless the lower the chance of conception, and as time runs out anxiety increases. Purchasing authorities are beginning to recognise the importance of subfertility and to purchase services for assisted conception. The techniques themselves are coming under increasing scrutiny from randomised trials. For example, 10 such studies have evaluated the effects of down regulation of the pituitary gland before ovulation was induced, and these have confirmed that this treatment is effective in doubling the rate of conception and halving the number of cancelled cycles.

General practitioners need information about the effectiveness of treatments for subfertility so that they can advise patients and contribute to any discussion about the level of funding of subfertility services. The newly published bulletin on the management of subfertility ${ }^{3}$ and the guidelines from the Royal College of Obstetricians and Gynaecologists on the topic ${ }^{4}$ will help such difficult choices.
We thank Professor Allan Templeton of Aberdeen and Dr Patrick Vandekerckhove of Leeds for their helpful comments.

RICHARD LILFORD

Professor of Obstetrics and Gynaecology

Department of Clinical Medicine,

University of Leeds,

Leeds LS2 9LN

GAVIN YOUNG General Practitioner

The Surgery,

Barn Croft,

Temple Sowerby,

Penrith CA10 1RZ

1 Greenhall E, Vessey M. The prevalence of subfertility: a review of the current confusion and a report of two new studies. Fertil Steril 1990;54:978-83.

2 Edelmann RJ, Connolly KJ. Psychological aspects of infertility. Br F Med Psychol 1986;59:1-11.

3 The management of subfertility. Effective Health Care. 1992; No 3(August): 1-24

Fertility Committee of the Royal College of Obstetricians and Gynaecologists. Infertility: guideline for practice. London:RCOG Press, 1992.

5 Bromham D, Balmer B, Clay R, Hamer R. Disenchantment with infertility services: a survey of patients in Yorkshire. Br f Family Planning 1988;14:3-8.

6 Lilford RJ, Dalton ME. Effectiveness of treatment for infertility. BMF 1987;295:155-6.

7 Hughes E, Fedorkow D, Daya S, Sagle M, Vandekerckhove P, Collins J. The routine use of gonadotropin releasing hormone agonists prior to IVF and GIFT: a meta-analysis of randomized controlled trials. Fertil Steril (in press).

\title{
Part time working and job sharing in the NHS
}

\author{
Some worthwhile progress but still a long way to go
}

More than a million people work in the NHS and three quarters of them are women. Faced with such a large female workforce and pressure from the Equal Opportunities Commission, ${ }^{1}$ the NHS Management Executive has created the NHS Women's Unit and issued a handbook of good practice, ${ }^{2}$ which includes large sections on improving opportunities for part time working. Because of their domestic commitments many women need to work part time and will sacrifice their career prospects, turning to unpopular specialties and non-career grades to balance their family and career. $^{3}$

Part time working for doctors in the hospital service has had to fit into tight controls on staffing and has proceeded from the top down. Since the 1960 s there have been several central directives, leading to the current nationally organised training schemes for registrars and senior registrars. ${ }^{45}$ Under the senior registrar scheme (PM(79)3) candidates are interviewed annually for a limited number of places in each specialty. Those successful in gaining manpower approval must arrange training with a local unit, convince the relevant college of their appointment's educational value, and get funds from the region. Just over a fifth of female senior registrars have graduated from this crash course in NHS bureaucracy and are working part time (Department of Health, personal communication). Of course, half time often means a 40 hour week. The faults of PM(79) 3 have been appreciated, and the new registrar arrangements $(\mathrm{EL}(91) 5)$, although similar, have been streamlined and are centrally funded, at least until 1995. Currently $11 \%$ of female registrars work part time, and the aim is to quadruple that number in five years. For senior house officers health authorities and trusts can set up part time posts without applying for central approval; $5 \%$ of female senior house officers work part time. No formal part time schemes exist for consultants, and full time working is the norm, with only $9 \%$ of all consultants having an NHS commitment of eight sessions or less.

In general practice trainees can work part time for two years, and about one in 10 women do so, with trainers getting half the training allowance. For principals in general practice partners may be full time, three quarter time, or half time. Around $15 \%$ of female principals are three quarter time partners, and fewer than $3 \%$ are half time. ${ }^{6}$ The retainer scheme is the medical profession's only scheme for managing a career break and is used by just 550 women, almost exclusively in general practice, doing up to two paid sessions a week.

There are no job sharing schemes as such, but the practice is now officially encouraged by the NHS Management Executive and has been a small scale success in different professions, specialties, and grades across the health service. ${ }^{8}$ It is attractive to employers, who do not have to restructure the service to accommodate part timers and who benefit from the bit more than half time that jobsharers do. Fears of excessive administrative and training costs and lack of continuity are largely unfounded. The big limitation is finding a partner and even with the job share registers set up by the BMA and several specialties this is likely to remain a minority solution for doctors. Some $1 \%$ of all principals in general practice now job share.

Comparing doctors with other NHS professionals-for example, the 320000 nurses-is interesting. In nursing, part time arrangements are evolving from the bottom up. Managers are offering staff a wide range of options-including limited hours, term time working, and local banks-and a third of nurses now work part time. This is usually, however, at the grade of staff nurse or below. Ward sisters wishing to work part time after maternity leave are frequently offered a lower grade, although sometimes job sharing will be explored at their former grade. ${ }^{9}$

Taken together, these options do not yet provide enough opportunities for part time working. Nearly three quarters of young women doctors would like to work part time when their children are young, ${ }^{10}$ but only $22 \%$ of female senior registrars are doing so. We must not forget the growing numbers of men 
who want to spend more time with their children or to retrain in another specialty, or the middle aged doctor with elderly dependants. Conversely, women may be inhibited from pursuing part time options for fear of damaging their careers or committing themselves to interminable training. The royal colleges remain rigid in their training requirements and insist that half time training is twice as long, although the trainees may be attending proportionately more educational sessions and have more time for reflection than their full time colleagues. Perhaps most important is the low value still placed on part time work and the reluctance to take it to the top, whether in nursing, general management, or medicine.

Part time working must now be considered integral to any staff planning exercise, not grafted on as an afterthought. The existing national schemes have achieved some of their objectives, notably a fall in female medical unemployment. The current high profile at the centre is welcome; only the Department of Health could encourage a conservative body like the Royal College of Surgeons to publicise part time training (as it is doing through its Women in Surgical Training Scheme). What we need now is more room for local initiatives and flexibility within the national staffing frameworks. Whether the new look market NHS will provide this flexibility is uncertain.

Doctors wanting to work part time can get information from the following sources: Women in Surgical Training, Royal College of Surgeons; Medical Women's Federation, Tavistock House North, Tavistock Square, London WC1; for trainees in general practicetheir regional adviser in general practice; for registrars and senior registrars - their regional postgraduate dean.

VIVIENNE VAN SOMEREN

Consultant Senior Lecturer in Child Health

Royal Free Hospital and School of Medicine, London NW3 2QG

1 Goss S, Brown H. Equal opponunities for women in the NHS. London: NHS Management Executive, 1991

2 NHS Management Executive. Women in the NHS: good practice handbook. London: NHS Management Executive, 1991

3 Day P. Women doctors: choice and constraints in policies for medical manpower. London: King's Fund, 1982.

4 Department of Health. Part-time opportunities for doctors in training. London: Department of Health, 1991.

Shore E. Part-time training in hospital medicine. Medical Woman 1991;10:6.

6 BMA. Equal opportunities in medicine. London: BMA, 1992

7 Toynton N Doctors' retainer scheme. BMF 1992;305:1378-9.

8 Meager N, Buchan J, Rees C. Fob-sharing in the National Health Service. Brighton: Institute of Manpower Studies, Unes

Manpower Studies, University of Sussex, 1989.
Buchan J. A share in the future. Nursing Times 1991;87(23):32-3.

10 Bolton-Maggs P, van Someren V, Lefford F. The need for part-time work: a survey of doctors 10 years after graduation. Br $\mathcal{F}$ Hosp Med 1988;39:413-8.

\section{Doctors' retainer scheme}

\section{Need for reform}

Few doctors are aware of the doctors' retainer scheme, and even fewer have used it. ${ }^{1}$ In the year ended 30 September 1991, 656 doctors belonged to the scheme in England and Wales (Department of Health, unpublished figures). The scheme has climbed up the medicopolitical agenda for a number of reasons, one of them being the publicity surrounding Opportunity 2000 and Virginia Bottomley's commitment to it. At the same time there has been a growing awareness of the loss of highly skilled, fully trained doctors and an increasing resolution by all parties to stop this.

Begun in 1972, the women doctors' retainer scheme became the doctors' retainer scheme in 1977 so that men could be admitted. The scheme is administered by the regional health authorities with clinical tutors, under the auspices of postgraduate deans and regional postgraduate education committees. Doctors in any specialty may use it, although women general practitioners predominate.

Retained doctors must be aged under 55, registered with the General Medical Council, and be members of a medical defence organisation. They must attend at least seven education sessions a year, take a professional journal, and work at least one half day a month up to a maximum of one day a week. ${ }^{2}$ In return they receive a retainer to help meet expenses associated with employment-which include child care, defence fees, GMC annual retention fee, professional membership, and fees for travel and courses.

The scheme officially has no fixed term of membership and annual renewal is at the discretion of the clinical tutor and the regional health authority. The maximum allowable term differs between authorities and may be anything from two to 15 years. A few doctors have undoubtedly abused the scheme-unpublished figures from the Department of Health from 1986 showed that some doctors had been on the scheme since its inception. Setting a rigid maximum of two years, as some regions have done, negates the point of the scheme to those making up most of its members-women doctors with children. (The average female doctor has slightly above the national average of children. $\left.{ }^{1}\right)$ Doctors join the scheme for an average of 2.5 years (Department of Health, unpublished figures); the proportion who return to full time medicine is unknown. Much more flexibility is desirable with each doctor being assessed annually to see if he or she needs to remain on the scheme or whether careers advice should be offered.

Given the scheme's predominance of general practitioners, it is debatable ${ }^{2}$ whether the clinical tutor is the best person to administer it. An alternative would be the regional adviser in general practice, with the postgraduate dean playing a larger part. Hospital doctors would benefit from a separate scheme more attuned to their needs; that few hospital doctors are on the scheme probably reflects the difficulty in funding and finding appropriate hospital posts.

The retainer is worth $£ 290$ a year and covers only a small part of the expenses associated with employment. General practitioners on the retainer scheme and assistants in general practice are now the only groups of doctors working in the NHS who must pay their own defence fees; specific provision should be made for these, distinct from the retainer fee.

The family health services authorities pay the practice employing a retained doctor a flat rate of $£ 38.75$ a week, regardless of whether one or two sessions are worked. Retained doctors will therefore find it easier, if working two sessions a week, to obtain employment in two separate practices, which is clearly not in their best professional interest. The fee for employing a retained doctor should be paid on a sessional basis.

The employing practice pays the retained doctor a sessional rate. Although most practices pay locum rates recommended by the BMA, this is not always the case, and exploitation may result. Practices should be obliged to pay a nationally agreed minimum rate of pay. Unless the rates of pay are improved the cost of child care will continue to be a major obstacle to many women joining the scheme. Tax relief for the costs of child care would help, but as this is unlikely, reconsidering the rates of pay is even more imperative. 